\title{
Perilaku Orangtua Siswa Sekolah Dasar Sigaranten Sukabumi dalam Penanganan Infestasi Kutu Kepala
}

\author{
Ratna Dewi Indi Astuti, ${ }^{1}$ Intan Aulia ${ }^{2}$ \\ Departemen Parasitologi Fakultas Kedokteran Universitas Islam Bandung
}

\begin{abstract}
Abstrak
Anak usia sekolah dasar masih banyak yang terinfestasi kutu kepala (Pediculosis capitis) saat ini. Infestasi kutu kepala ini menimbulkan rasa gatal yang dapat berkembang menjadi infeksi sekunder dan gangguan tidur, belajar, maupun sosial. Beragam upaya pengobatan dilakukan di masyarakat dan hingga saat ini belum ada pedoman tetap dalam menangani infestasi kutu kepala. Penelitian ini bertujuan menganalisis perilaku masyarakat dalam menangani infestasi kutu kepala dan hasil perilaku tersebut yang dilihat dari angka kejadian infestasi kutu kepala. Penyebaran kuesioner mengenai perilaku pengobatan infestasi kutu kepala pada masyarakat dilakukan pada 69 orangtua siswa kelas 5 Sekolah Dasar Negeri Sigaranten Sukabumi pada bulan Juni 2018. Kejadian infestasi kutu kepala pada siswa didapatkan dengan pemeriksaan rambut dan kulit kepala selama 5 menit setelah mendapat persetujuan orangtua siswa. Pada penelitian ini didapatkan 38 siswa yang terinfestasi kutu kepala (55\%). Sebagian besar orangtua melakukan pengobatan infestasi kutu kepala pada anaknya dengan cara menyerit (64\%). Tidak ada perbedaan bermakna perilaku penanganan infestasi dengan menyerit, menggunakan obat kutu, dan pengambilan kutu manual berupa kejadian infestasi kutu kepala pada siswa $(\mathrm{p}=0,054)$. Simpulan, perilaku pengobatan kutu kepala oleh orangtua pada anaknya sebagian besar belum efektif karena 55\% siswa masih terinfestasi kutu kepala.
\end{abstract}

Kata kunci: Infestasi, kutu kepala, penanganan, perilaku

\section{Behavior of Parents of Sukabumi Sagaranten Primary School Students in Handling Head Lice Infestation}

\begin{abstract}
There are still many primary school-age children who are infested with head lice (Pediculosis capitis). Head lice infestations cause itching which can develop into secondary infections and sleep, learning and social disorders. There are various efforts for treating head lice infestation in the community and until now there is no guideline treatment for head lice infestations. This study aims to analyze the behavior of people in treating the head lice infestations and the result as seen from the incidence of head lice infestations. The questionnaire regarding the behavior of head lice infestation treatment in the community was carried out on 69 parents of 5 th grade students of Sigaranten Sukabumi Elementary School in June 2018. The incidence of head lice infestation in students was obtained by examining hair and scalp for 5 minutes after parents' approval. In this study 38 students were infected with head lice (55\%). The most parents treated head lice infestations by combing (64\%). There were no significant differences in behavior of treating head lice by comb, pediculocid, and manual removal to the incidence of head lice infestation in students $(\mathrm{p}=0.054)$. In conclusion, the behavior of head lice treatment by parents to their children is ineffective because $55 \%$ of students are still infested with head lice
\end{abstract}

Keywords: Behavior, head lice, infestation, treatment

Korespondensi: Ratna Dewi Indi Astuti. Departemen Parasitologi, Fakultas Kedokteran, Universitas Islam Bandung, Jalan Taman Sari No. 22, 40116, Kota Bandung, Provinsi Jawab, dr_ratnadewi@yahoo.com 


\section{Pendahuluan}

Infestasi kutu kepala (Pediculosis capitis) yang disebabkan oleh Pediculus humanus var capitis masih menjadi masalah di dunia dan juga Indonesia. Infestasi kutu kepala terjadi terutama pada anak usia sekolah dasar. ${ }^{1-5}$ Angka prevalensi infestasi kutu kepala di beberapa negara bervariasi. ${ }^{2}$ Angka kejadian infestasi kutu rambut pada anak usia sekolah di Mesir 20,8\%, Arab Saudi 17,8\%, ${ }^{6}$ Malaysia 15,3\%,7 dan Thailand 23,48\%. ${ }^{8}$ Angka kejadian infestasi kutu kepala pada usia sekolah dasar di Indonesia digambarkan pada beberapa penelitian. Angka kejadian infestasi kutu kepala pada salah satu sekolah dasar di Pekan Baru tercatat 39.3\%. ${ }^{3}$ Penelitian di salah satu sekolah dasar di Bandung mendapatkan angka kejadian infestasi kutu kepala sebesar 77,14\%. ${ }^{9}$ Anak usia sekolah dasar memiliki kontak langsung yang erat dengan teman maupun dengan keluarga sehingga meningkatkan risiko kejadian pada usia tersebut. .,10 $^{8}$

Walaupun kutu kepala tidak dapat terbang, kutu kepala mempunyai kemampuan merayap yang baik sehingga kutu kepala sangat mudah menyebar dari satu penderita ke orang lain secara kontak langsung dan kontak tidak langsung, misalnya melalui sisir dan pakaian. ${ }^{11}$

Kutu kepala tersebut mendapat nutrisi dengan menghisap darah dari kulit kepala penderita. Air liur kutu yang dilepaskan pada saat kutu menghisap darah akan menimbulkan reaksi sensitisasi yang menyebabkan gatal pada kulit kepala penderita. ${ }^{11}$ Gatal yang ditimbulkan dapat menyebabkan gangguan konsentrasi belajar, gangguan tidur, dan luka kulit kepala akibat garukan yang dapat menimbulkan infeksi sekunder., ${ }^{4,10,11}$ Di negara negara maju, infestasi kutu kepala menimbulkan pandangan sosial yang negatif sehingga menyebabkan gangguan kepercayaan diri dan ketidakhadiran penderita di sekolah. 2,6,12

Hingga saat ini belum ada protokol tetap dalam mengatasi infestasi kutu kepala pada anak usia sekolah dasar. ${ }^{13}$ Beragam pengobatan yang dilakukan untuk mengatasi infestasi kutu kepala di masyarakat adalah dengan mempergunakan pedikulosid seperti permetrin $1 \%$ yang dapat dibeli di toko obat, dengan cara mekanik seperti menggunakan sisir serit maupun dengan tangan, ataupun mencukur habis rambut anak laki-laki yang terkena infestasi kutu rambut. ${ }^{11,14,15}$

Keberagaman pengobatan kutu rambut itu dapat dipilih dan dilaksanakan mandiri oleh masyarakat. Penelitian ini bertujuan untuk menganalisis perilaku masyarakat dalam menangani infestasi kutu kepala dan hasil perilaku tersebut yang dilihat dari angka kejadian infestasi kutu kepala.

\section{Metode}

Penelitian ini sudah memperoleh persetujuan etik dari Komite Etik Penelitian Kesehatan Fakultas Kedokteran Universitas Islam Bandung dengan nomor 296/Komite Etik FK/III/2018. Penyebaran kuesioner mengenai perilaku pengobatan infestasi kutu kepala pada masyarakat dilakukan pada 69 orangtua siswa kelas 5 Sekolah Dasar Negeri Sigaranten Sukabumi pada bulan Juni 2018. Kejadian infestasi kutu kepala pada siswa didapatkan dengan pemeriksaan rambut dan kulit kepala selama 5 menit setelah mendapat persetujuan orangtua siswa. Infestasi kutu kepala pada siswa ditegakkan dengan ditemukannya kutu dewasa dan atau nimfa maupun telur kutu yang dapat menetas. Telur kutu yang dapat menetas adalah telur kutu yang terletak kurang dari $1 \mathrm{~cm}$ dari kulit kepala siswa, berwarna coklat merah, dan berkilau. ${ }^{8}$ Data disajikan dalam tabel dan dianalisis dengan chi-square.

\section{Hasil}

Pada penelitian ini didapatkan 38 orang siswa yang terinfestasi kutu kepala atau (55\%). Hasil pengisian kuesioner orangtua menyatakan bahwa sebagian besar orangtua melakukan pengobatan infestasi kutu kepala pada anaknya dengan cara menyerit (64\%).

\begin{tabular}{lccc} 
Tabel & \multicolumn{3}{c}{$\begin{array}{c}\text { Perilaku Pengobatan Kutu Kepala dan } \\
\text { Kejadian Infestasi Kutu Kepala }\end{array}$} \\
\cline { 1 - 2 } $\begin{array}{lcc}\text { Peralatan } \\
\text { Pengobatan }\end{array}$ & \multicolumn{2}{c}{$\begin{array}{c}\text { Infestasi Kutu } \\
\text { Kepala }\end{array}$} & \\
\cline { 2 - 3 } & $\begin{array}{c}\text { Positif } \\
\mathbf{n = 3 8}\end{array}$ & $\begin{array}{c}\text { Negatif } \\
\mathbf{n = 3 1}\end{array}$ & Total \\
\hline Menggunakan obat & 9 & 6 & 15 \\
Menggunakan sisir & $(13 \%)$ & $(8,7 \%)$ & $(22 \%)$ \\
serit & 27 & 17 & 44 \\
Mengambil kutu & $(39 \%)$ & $(25 \%)$ & $(64 \%)$ \\
dengan tangan & 2 & 8 & 10 \\
\hline
\end{tabular}

Tidak ada perbedaan bermakna antara ketiga perilaku pengobatan tersebut dan kejadian infestasi kutu kepala pada siswa $(\mathrm{p}=0,054)$. Perilaku pengobatan infestasi kutu kepala dengan mengambil kutu menggunakan tangan lebih baik daripada pengobatan menggunakan permetrin $(\mathrm{p}=0,048)$ maupun dengan penggunaan sisir serit $(\mathrm{p}=0,018)$. Namun, perilaku pengobatan infestasi kutu kepala mengunakan sisir serit tidak lebih baik daripada penggunaan permetrin $(\mathrm{p}=0,925)$.

\section{Pembahasan}

Pada penelitian ini penggunaan sisir serit merupakan pengobatan yang paling banyak dipilih oleh orangtua untuk mengatasi infestasi kutu rambut. Penggunaan sisir serit direkomendasikan karena relatif murah, mudah didapatkan, dan digunakan oleh masyarakat. ${ }^{11,13}$ Penggunaan sisir serit banyak digunakan sekarang ini karena masalah resistensi insektisida semakin banyak dilaporkan akhir-akhir ini. ${ }^{13,15}$ Penyisiran rambut dengan sisir serit dilakukan saat rambut basah dan disarankan menggunakan kondisioner rambut untuk mengurangi ketidaknyamanan pada waktu menggunakannya..$^{10,11}$

Penyisiran rambut pada saat kering dinyatakan tidak efektif. Penyisiran dilakukan sebanyak 2-3 kali dalam seminggu selama kurang lebih $15-30$ menit atau sampai tidak ditemukannya kutu. Penggunaan sisir serit ini disarankan dilakukan terus secara berkala 
untuk deteksi dini dan pengobatan. ${ }^{11}$ Sisir serit harus dibersihkan setelah digunakan agar tidak menjadi sumber infeksi bagi penderita dan orang lain. ${ }^{15}$

Pengobatan lain yang dilakukan oleh orangtua siswa pada penelitian ini adalah menggunakan obat kutu. Obat kutu yang banyak tersedia di toko obat Indonesia berisi permetrin 1\%. Penggunaan permetrin setelah keramas selama 20 menit efektif membunuh kutu rambut, namun tidak efektif terhadap telur kutu. Oleh karena permetrin tidak efektif terhadap telur maka pengobatan perlu diulang seminggu kemudian ketika telur-telur telah menetas menjadi larva dan dapat terbunuh oleh permetrin..$^{14,15}$ Namun, saat ini keefektifan penggunaan permetrin 1\% menurun karena resistensi terhadap permetrin yang meningkat. ${ }^{14}$

Pengambilan kutu secara manual masih menjadi pilihan sebagian orangtua siswa pada penelitian ini. Cara ini merupakan cara yang diturunkan secara turun temurun dan merupakan cara yang pertama kali dilakukan untuk mengatasi kutu kepala. Pengambilan kutu secara manual ini menghabiskan waktu dan kurang efektif. ${ }^{11,14}$ Pembunuhan kutu dengan tangan juga tidak dianjurkan karena dapat menyebabkan bakteri masuk melalui kulit. ${ }^{14}$

Perilaku pengobatan kutu kepala yang dilakukan oleh orangtua terhadap anaknya pada penelitian ini belum efektif. Beberapa faktor ditengarai sebagai penyebab belum efektifnya pengobatan infestasi kutu kepala adalah belum tepatnya pengobatan sesuai dengan anjuran penggunaan, resistensi kutu terhadap permetrin, tidak efektifnya permetrin terhadap telur kutu, juga tidak dilakukan pengulangan pengobatan, penggunaan sisir serit yang tidak tepat, dan reinfeksi. ${ }^{10,15}$ Reinfeksi merupakan masalah utama dalam mengatasi infestasi kutu kepala dalam suatu populasi. Pemutusan transmisi merupakan faktor penting yang mendukung keberhasilan pengobatan. ${ }^{5}$ Deteksi dini menggunakan sisir serit dan pengobatan segera merupakan langkah yang perlu diterapkan agar penyebaran infestasi kutu kepala dapat tertangani.11

Pada penelitian ini dinyatakan pengambilan kutu secara manual merupakan cara yang paling efektif. Hal ini tidak sesuai dengan pernyataan sebelumnya yang menyatakan bahwa pengambilan kutu secara manual tidak efektif ${ }^{14}$ dan peneliti juga tidak menyarankan cara ini karena memerlukan waktu dan upaya yang lebih rumit. ${ }^{11}$ Pada penelitian ini juga tidak didapatkan perbedaan angka kejadian infestasi kutu kepala pada siswa yang ditangani dengan permetrin maupun dengan sisir serit oleh orangtuanya. Hal ini sesuai dengan pernyataan sebelumnya yang menyatakan belum ada cara yang dikatakan lebih efektif dalam mengatasi infestasi kutu kepala. Penelitan sebelumnya ada yang menyatakan bahwa penggunaan sisir serit lebih efektif dua kali lipat dibanding dengan penggunaan permetrin, namun beberapa penelitian juga ada yang menyatakan sisir sisir serit tidak lebih baik dari permetrin. ${ }^{15}$ Hasil pada penelitian ini terdapat bias yang besar mengingat tidak dilakukannya intervensi. Namun, berdasar atas observasi yang menyatakan tidak terdapat perbedaan hasil perilaku pengobatan menggunakan sisir serit dan permetrin, peneliti menganjurkan penggunaan sisir serit mengingat sisir serit murah dan mudah didapat, dan relatif lebih aman karena tidak menggunakan bahan kimia serta tidak memicu resistensi pedikulosid. ${ }^{11,13}$

Namun, perilaku pengobatan kutu kepala oleh orangtua pada anaknya sebagian besar belum efektif karena 55\% siswa masih terinfestasi kutu kepala.

\section{Simpulan}

Perilaku pengobatan kutu kepala oleh orangtua siswa SDN Sigaranten Sukabumi pada anaknya sebagian besar belum efektif.

\section{Ucapan Terima Kasih}

Terima kasih kepada orangtua siswa SD Sigaranten Sukabumi yang telah menjadi responden penelitian.

\section{Daftar Pustaka}

1. CDC. Head lice [internet]. Atlanta USA: CDC.2013. [diperbaharui 24 September 2013; diunduh 16 April 2019]. Tersedia dari: https://www.cdc.gov/ parasites/lice/head/epi.html

2. Canyon DV, Canyon C, Milani S. Parental and child attitudes towards pediculosis are a major of reinfection. Open Dermatol J. 2014 April;8:24-8.

3. Zulinda A, Yolazenia, Zahtamal. Faktor-faktor yang mempengaruhi kejadian pedikulosis kapitis pada murid kelas II, IV, V dan VI SDN 019 Tebing Tinggi Okura Kecamatan Rumani Pesisir Pekanbaru. JIK. 2010 Mar;4(1):65-9.

4. Hardiyanti NI, Kurniawan B, Mutiara H, Suwandi JF. Penatalaksanaan pedikulosis kapitis. Majority. 2015 Des;4(9):47-52.

5. Canyon DV, Canyon C, Milani S. Characterizing the nature of human carriers of head lice. Open Dermatol J. 2014;8:29-31.

6. Allam NA, AL Megrin WA, Alkeridis LA. Abdellah $\mathrm{F}$ model to banishing social stigma of head lice among school students. Sci J Clin Med. 2016 Feb;5(1):1-11.

7. Tohit NFM, Rumpal L, Mun-Sann L. Prevalence and predictors of pediculosis capitis among primary school children in Hulu Langat, Selangor. Selangor Med J Malaysia. 2017 Feb;72(1):12-7.

8. Rassami W, Soonwera M. Epidemiology of pediculosis capitis among school children in the eastern area of Bangkok, Thailand. Asian Pasific J Trop Biomed. 2012 Nov;2(11):901-4.

9. Samsiah N, Astuti RDI, Rathomi HS. Hubungan derajat infestasi dan gejala gatal terhadap perilaku pengobatan Pediculosis capitis pada murid kelas I SDN Pelesiran Kota Bandung. Prosiding Pendidikan Dokter Spesia Unisba. 2017 Agustus;3(2):53-60.

10. Mumcuoglu KY, Gilead l, Ingber A. New insight pediculosis and scabies. Expert Rev Dermatol. 2009 Jun;4(3):285-302.

11. Madke B, Khopkar U. Pediculosis capitis: an update. Indian J Dermatol Venerol Leprol. 2012 Jul;78(4):429-38.

12. Madeira NG, de Souza PAT, Diniz RES. Perception 
and action of teachers and head lice in school. Revista Electronica Ensenanza de las Ciencias. 2015;14(2):119-30.

13. Stichele RHV, Gysssels L, Bracke C, Meersschaut F, Blokland I, Wittouck E, dkk. Wet combing for head lice: feasibility in masscreening, treatment preference and outcome. J Royal Soc Med. 2002 Jul;95:348-52.
14. Sangare AK, Doumbo OK, Raoult D. Management and treatment of human lice. Biomed Res Int. 2016. DOI 10.1155/2016/8962685

15. Verma P, Namdeo C. Treatment of pediculosis capitis. Indian J Dermatol [internet]. 2015 MayJun;6o(3):238-247. [diunduh 2 Okt 2018] Tersedia dari: doi 10.4103/0019-5154.156339 